\title{
Luminosity in the stream of consciousness
}

\author{
David Jenkins ${ }^{1}$
}

Received: 25 July 2017 / Accepted: 1 May 2018 / Published online: 11 May 2018

(C) The Author(s) 2018

\begin{abstract}
Williamson's (Knowledge and its limits, Oxford University Press, Oxford, 2000, Chapter 4) "anti-luminosity" argument aims to establish that there are no significant luminous conditions. "Far from forming a cognitive home", luminous conditions are mere "curiosities" (2000, p. 109). Even supposing Williamson's argument succeeds in showing that there are no significant luminous states his conclusion has not thereby been established. When it comes to determining what is luminous, mental events and processes are among the best candidates. It is events and processes, after all, which constitute the stream of consciousness. Judgment, for instance, is plausibly self-conscious. If I am judging then plausibly I must know that I am. Similarly, deliberation is plausibly self-conscious. To be deliberating about some matter I plausibly must know that I am. That one is judging and that one is deliberating are thus plausibly luminous conditions. Furthermore, I argue, Williamson's anti-luminosity argument fails to speak against this suggestion. This reveals that Williamson's argument is more limited in scope than has been thought—something likely missed due to a misplaced focus on mental states in the luminosity debate as well as in epistemology and the philosophy of mind more generally. For all Williamson shows, there may be luminous events and processes of a sort apt to constitute a cognitive home. I conclude by considering how the anti-luminosity argument might be reinstated in the judgment case and argue that the natural way to do so fails.
\end{abstract}

Keywords Luminosity - Self-consciousness - Stream of consciousness · Ontology of mind $\cdot$ Judgment $\cdot$ Deliberation

$凶$ David Jenkins

david.jenkins@kcl.ac.uk

1 King's College London, Strand, London WC2R 2LS, UK 


\section{Introduction}

My aim is to argue that Williamson's (2000, Chapter 4) "anti-luminosity" argument is more limited in scope than it has been taken to be. Even supposing that the argument establishes that luminous states are mere curiosities, it fails to show that the same is true of luminous events and processes. Furthermore, I suggest, there plausibly are significant examples of luminous events and processes. The onus is thus on the advocate of anti-luminosity arguments to explain why we should think otherwise.

In Sect. 2, I outline Williamson's anti-luminosity argument. In Sect. 3, I consider the conclusion that the anti-luminosity argument is taken to yield. Advocates of the argument take it to show that there are no significant luminous states. But the conclusion then drawn is that there are no significant luminous conditions. However, I point out, to establish the latter the anti-luminosity argument needs to do more than show that there are no significant luminous states. It must show that there are also no significant luminous events or processes. In Sect. 4, I draw attention to plausible candidate luminous events and processes. Judgment is plausibly a kind of luminous event, whilst deliberation is plausibly a kind of luminous process. Furthermore, as I explain in Sect. 5, Williamson's argument fails to speak against the suggestion that judgment and deliberation are luminous. In Sect. 6, I consider how the anti-luminosity argument might be reinstated against the suggestion that judgment is luminous. I argue that the natural way to do so fails. I conclude, in Sect. 7, that for all the anti-luminosity argument shows there may be luminous events and processes of a sort apt to constitute a cognitive home.

\section{The anti-luminosity argument}

It will help to begin with Williamson's terminology:

A case is a possible total state of a system, the system consisting of an agent at a time paired with an external environment, which may of course contain other subjects. ...

A condition obtains or fails to obtain in each case. Conditions are specified by 'that' clauses. The pronoun 'one' and the present tense in such clauses refer to the distinguished agent and time respectively (2000, p. 62).

A condition $C$ is then "luminous" iff:

For every case $\alpha$, if in $\alpha C$ obtains, then in $\alpha$ one is in a position to know that $C$ obtains (2000, p. 95).

Of course, most conditions are not luminous. But it is plausible to think that some are. Williamson, for instance, suggests that that one feels cold and that it looks to one as though there is a purple patch ahead are on first pass plausibly conditions which one is in a position to know obtain whenever they do. 
Williamson (2000, pp. 107-108) does admit that some "trivial conditions" are luminous. Trivial conditions include those which obtain in all cases ${ }^{1}$ and those which obtain in none. Williamson's (2000, Chapter 4) claim is that there are no significant and non-trivial luminous conditions. ${ }^{2} \mathrm{He}$ illustrates the point with the condition that one feels cold, since, he claims:

It appears to have about as good a chance as any non-trivial condition of being luminous (2000, p. 96).

Williamson sets things up as follows. Suppose that $t_{0}, t_{1}, \ldots, t_{n}$ is a series of times at $1 \mathrm{~ms}$ intervals beginning at dawn and ending at noon. $\alpha_{i}$ is a case at $t_{i}(0 \leq i \leq \mathrm{n})$. At dawn one feels cold and at noon one feels hot. The change in how one feels is also gradual such that how things are from one's point of view in any case, $\alpha_{i}$, is imperceptibly different to how things are for one in $\alpha_{i+1}$. Furthermore, one carefully considers how one feels throughout $t_{0}$ to $t_{n}$.

Williamson imposes the following safety condition on knowing that one feels cold in $\alpha_{i}$ :

( $\left.\mathrm{I}_{i}\right)$ If in $\alpha_{i}$, one knows that one feels cold, then in $\alpha_{i+1}$ one feels cold (2000, p. 97).

One could not know that one feels cold in a case $\alpha_{i}$ if in $\alpha_{i+1}$ one does not feel cold. In general, one cannot know that $p$ in a case if $p$ could so easily have been false in circumstances which would be imperceptibly different from one's point of view to those which one is in fact in.

Williamson's argument can now be run as a reductio as follows (see 2000, pp. 96-98). Suppose that feeling cold is luminous and consider case $\alpha_{0}$. One feels cold in $\alpha_{0}$. Given one is considering the matter and feeling cold is luminous one thereby knows that one feels cold in $\alpha_{0}$. By $\left(\mathrm{I}_{i}\right)$ one must thereby feel cold in $\alpha_{1}$. Given one is considering the matter and feeling cold is luminous one thereby knows that one feels cold in $\alpha_{1}$. By $\left(\mathrm{I}_{i}\right)$ again one must thereby feel cold in $\alpha_{2}$. And again, given one is considering the matter and feeling cold is luminous one thereby knows that one feels cold in $\alpha_{2}$. By $\left(\mathrm{I}_{i}\right)$ once again one must thereby feel cold in $\alpha_{3}$. We can continue like this and arrive at the conclusion that one feels cold in $\alpha_{n}$, which by hypothesis one does not. Given $\left(\mathrm{I}_{i}\right)$ we have a reductio of the claim that feeling cold is luminous. ${ }^{3}$

Such reasoning can be applied to any condition for which it is possible to have a series of cases as above. It can be applied to any condition for which it is possible to have a series of times where the condition obtains at one point and does not at another, and where the change in question occurs gradually — so that an analogue of $\left(\mathrm{I}_{i}\right)$ plausibly holds. And this will be possible for any condition of a sort which can be gradually gained or lost such that the change in how things are from one time to the next is imperceptibly small from one's own point of view. Williamson (2000, pp.

\footnotetext{
${ }^{1}$ So long as they are "presented in a simple tautological guise" (see Williamson 2000, pp. 107-108).

2 Hence in what follows by 'condition' I will mean only non-trivial conditions.

${ }^{3}$ For refinement and defence of the argument see Srinivasan (2015). The complications here will not matter in what follows since I grant that Williamson's argument is effective and only question its scope of application.
} 
107-109) argues, for instance, that analogous arguments will apply in the cases of the conditions that one is in pain and that it looks to one as though there is a purple patch ahead. For cases in which one is in pain or in which things look purple can gradually give way to cases in which things are otherwise.

\section{The standard take}

Williamson's argument is typically taken to lead to the conclusion that there are no significant luminous states and thus no significant luminous mental states. ${ }^{4}$ Mental states appear to be the best candidates for luminous states. And all mental states appear to be of the sort which generate anti-luminosity arguments (e.g. belief, knowledge, intention, ...).

That states have been the focus in the luminosity debate is evident from how Williamson's conclusion is typically summed up. Ramachandran, for instance, sums things up by saying that "Williamson (2000) reckons that hardly any mental state is "luminous"” (2009, p. 659 my emphasis). Weatherson similarly sums up by saying that "Williamson has recently argued that few mental states are luminous" (2004, p. 373 my emphasis), whilst Wong says that Williamson's conclusions is "that no mental states are such that when we are in them we are in a position to know that we are in them" (2008, p. 536 my emphasis). Williamson (2000, p. 93) himself even begins his discussion by stating that he will argue that there is no core set of luminous mental states. However, Williamson (2000, p. 95ff.) swiftly shifts focus to the broader question of whether there are any significant luminous conditions. He states that the question which concerns him is:

what conditions, if any, are in fact luminous? (2000, p. 95).

In line with this, the conclusion drawn is that potential examples of luminous conditions:

constitute a very minor limitation on the generality of the [anti-luminosity] argument (2000, p. 109).

Although there may be some luminous conditions they are mere "curiosities" and are "remove from our ordinary interests" (2000, p. 109). It is clear that Williamson believes that if his argument succeeds then it reveals that there are not just no significant luminous states but no significant luminous conditions.

Williamson thereby takes himself to be undermining what many have taken to be a crucial Cartesian insight. It is a mistake to think that we have a "cognitive home"- that there is a significant domain with respect to which we are always in a position to know what is the case. As Srinivasan puts it, the conclusion drawn is taken to have as a consequence that:

the common picture of the phenomenal realm as one of privileged access turns out to be a Cartesian orthodoxy from which philosophy must be cleansed (2015, p. 294).

\footnotetext{
${ }^{4}$ Where a luminous state is a state such that if one is in it then one is in a position to know that one is.
} 
But there is more to one's mind than one's mental states - there are also mental events and processes (Steward 1997; see also O'Shaughnessy 2000, pt. 1; Soteriou 2013) — and, as I will argue, Williamson's anti-luminosity argument does not apply to significant examples of these latter aspects of the mind. Mental events and processes are kinds of mental occurrences. How the distinction between states and occurrences is to be drawn and how, within the latter, the distinction between events and processes is to be a drawn is a matter of controversy (e.g. Crowther 2011; Hornsby 2012; Steward 2013). What is nonetheless clear is that there is a distinction to be made between what occurs/happens/unfolds at times or for periods time and what merely obtains at times or for periods of time. States merely obtain at times or for periods of time, whereas events and processes occur/happen/unfold at times or for periods of time. What is also clear is that, as well as mental states (e.g. beliefs, intentions), there are mental events (e.g. judgments, noticing) and mental processes (e.g. deliberation, imagining). When one judges, for instance, one's judgment is an event which thereby happens at a time. Similarly, when one deliberates one's deliberation is a process which is thereby occurring for some period of time and which unfolds over that time. Furthermore, such events and processes should have been among the most plausible candidates for being luminous all along. ${ }^{5}$ After all, it is mental occurrences of this sort which constitute the stream of consciousness. The stream of consciousness, that is, is constituted by conscious events which occur at times and by conscious process which unfold or develop over time (Crane 2013, sec. 4; O'Shaughnessy 2000, pp. 42-47). And that such events and processes constitute the stream of consciousness makes it plausible that there are luminous events and processes, and thus that there are corresponding luminous conditions. Crucially, this claim has not been undermined, even if it is admitted that Williamson's anti-luminosity argument reveals that there are no luminous states.

\section{Luminous events and processes}

If Williamson's anti-luminosity argument is to have the scope it is alleged to have then it must apply to plausible candidates for luminous events and processes. I will consider one of each. Judgment is plausibly a kind of luminous event because plausibly, if I am judging then I must know that I am. Deliberation, meanwhile, is plausibly a kind of luminous process. This is because plausibly if I am deliberating then I must know that I am. I will present a case for thinking that judgment is a kind of luminous event and that deliberation is kind of luminous process. However, as noted, the ultimate aim is only to identify a mistaken understanding of the scope of Williamson's argument. To do so, there is no need to establish that judgments are in fact luminous events, nor that deliberation is in fact a luminous process. Williamson's argument is alleged to show that they cannot be. The dialectical situation is such that showing that Williamson's argument fails to apply in the case of some significant and plausibly luminous condition suffices to undermine his claim to have established his conclusion.

\footnotetext{
5 Where a luminous event is an event which is such that if it is an event of which one is the subject, then one is in a position to know that it is occurring. Similarly, a luminous process is a process which is such that if it is a process of which one is the subject, then one in a position to know that it is occurring.
} 
Consider the judgment case first. Plausibly, I have suggested, if I am judging then I must know that I am. Judgment, that is, is plausibly self-conscious. Judgment's being something which we consciously do makes this suggestion highly plausible. The fact that judgments are apt to occur as constituents of self-conscious activities makes the suggestion more plausible still. I might, for instance, conclude self-conscious deliberation about whether $p$ by judging that $p$. I will typically thereby know that I have concluded my deliberation. Furthermore, it is unclear how I could know that I have done so unless I know that I have judged that $p$. And it is unclear how I could know that I have judged that $p$ unless I knew that I was judging that $p$ when I concluded my deliberation by doing so. It seems that judgment needs to be self-conscious in order for it to play its role in such self-conscious deliberation.

Some might worry about generalising on the basis of the above in order to conclude that all judgment is self-conscious. But more can be said to make the suggestion plausible. Judgment is a kind of conscious act of acceptance. There are various other kinds of conscious acts of acceptance. In consciously accepting $p$, for instance, I might be judging that $p$, supposing that $p$, or assuming that $p$ for practical purposes. One way to further bolster the plausibility of the suggestion that judgment is self-conscious is by asking what makes it that case that my act of acceptance is one of judging, rather than, say, merely supposing, when I judge that $p$. A promising way to answer this question is to say that what I am up to when I judge that $p$ is settled by what I take myself to be up to. After all, if I do not even take myself to be judging that $p$ when I consciously accept $p$ then plausibly I am not judging that $p$ whatsoever (c.f. Soteriou 2013, p. 242). Furthermore, this is plausibly true because when in accepting $p$ I am judging that $p$ the event is one of judging only because I take it that I am judging. My taking it that I am judging that $p$ when accepting $p$ is plausibly what settles that the act in question is a judging of that $p$. On this view when I judge that $p$ I must believe that I am doing so, where this belief settles that I am in fact judging that $p$. Plausibly I thereby know that I am judging that $p$ whenever I do so (c.f. Soteriou 2013, pp. 238-251). Judgment is in this way self-conscious and thus that one is judging is a luminous condition.

Soteriou (2013, Chapter 10) thinks the above is correct because he endorses the following view. When one is judging that $p$ in accepting $p$ one must believe that one is judging where this belief constitutively depends on that one is accepting $p$ in the way in question. But this belief also determines that the act of acceptance is one of judging. Rödl (2007, 2013) also thinks that something along the lines of the above is correct. He maintains that taking it that one is judging that $p$ when one is doing so is just part of what it is to judge that $p$. This, he suggests, is because judging that $p$ and taking it that one is judging that $p$ are a single act of the mind. Of course, such views rest on contentious arguments. But all that is really crucial here is that the claim they capture - that judgment is self-conscious - is plausible and that it remains to be seen whether the claim is undermined by Williamson's argument.

As an anonymous reviewer noted, there is a regress worry which some might have for the suggestion that judgment is self-conscious which is worth discussing, if only to set it aside. It might be thought that judgment's being self-conscious requires that whenever one makes a judgment one must judge that one is making a judgment. But if we suppose that this is correct then a regress clearly ensues. If judgment is self-conscious then one must know that one is judging whenever one judges. But if 
knowing that one is judging requires judging that one is doing so then this means that whenever one makes a judgment one must judge that one is making a judgment. But if judgment is self-conscious the latter judgment must thereby be self-conscious too. And if knowing that one is judging requires judging that one is doing so whenever one judges then this will again require a further judgment (that one is judging that one is judging). The suggestion that judgment is self-conscious and that knowing that one is judging requires judging that one is doing so clearly generates a vicious regress.

Coming to know does not always require conscious judgment in a mediating role (O'Shaughnessy 2000, p. 107; Soteriou 2013, p. 231). We can and do come to know things without doing so by making conscious judgments. Given this, the lesson from the above regress is a simple one. We should deny that in order to come to be aware of what one is doing when one makes a judgment one must make a further judgment about what one is doing. One's knowledge of what one is doing when one is judging must be understood as "a silent or non-conscious partner" to one's judging (O'Shaughnessy 2000, p. 106). One knows that one is judging when one does so, that is, where being aware of what one is doing in this way does not require the occurrence of a further event of judging and thus a further occupant of the stream of consciousness.

Consider next the deliberation case. Plausibly, I have suggested, if I am deliberating then I must know that I am. Deliberation, that is, is plausibly self-conscious. This is so because deliberation is a kind of conscious activity. ${ }^{6}$ Suppose, for instance, that I am deliberating about whether $p$. Plausibly I must know that I am doing so in order to be doing so actively and consciously. If at some point I lose track of that I am deliberating about whether $p$ then plausibly that is simply no longer something which I am consciously and actively doing. This might be because I end up deliberating about something else. But if I do not know that I am deliberating about anything then plausibly I am not consciously and actively deliberating whatsoever. And, since deliberation is a kind of conscious activity, that is just for me to not be deliberating at all.

A concrete example may help to illustrate the point. Suppose that I am deliberating to figure out the quickest way home. I judge that the train would take $30 \mathrm{~min}$ and that the bus would take an hour. I then judge there is no quicker way home. Finally, I conclude that the train is the quickest way home. Now suppose that things went differently and that when I judged that the bus would take an hour I lost track of what I was doing. I no longer believed that I was trying to figure out the quickest way home. If that were the case then plausibly my judgment would not have qualified as a constituent of a process of deliberation to find out the quickest way home. If I lose track of that I am trying to find out the quickest way home then that is no longer something which I am doing. And if I lose track of that I am deliberating whatsoever then by the same token I am no longer doing so whatsoever.

Some might resist the claim that I must know that I am deliberating in order to be doing so whatsoever. After all, as an anonymous reviewer pointed out, people do often enough say things like 'I spent five minutes staring at the map before I remembered

\footnotetext{
6 To assume that deliberation is a kind of conscious activity is to side with Chrisman (2016), O'Shaughnessy (2000) and Soteriou (2013) against Strawson (2003). Although there are challenges when it comes to understanding how deliberation could be a kind of conscious activity these are challenges which, I believe, can be met and which are best dealt with elsewhere (see my 2018).
} 
that I was trying to figure out the quickest way home'. I could attempt to explain away the appearance of such counterexamples. But more may need to be said in defence of the claim that deliberation must be self-conscious in order to motivate doing so.

Deliberation is a kind of conscious process with series of events as constituents. I might, for instance, judge that $p$ at $t_{1}$, suppose that $q$ at $t_{2}$, and then infer $r$ at $t_{3}$, deliberating about whether $r$ by doing so. When I suppose that $q$ at $t_{2}$ I deliberate by doing so and when I infer $r$ at $t_{3}$ I deliberate by doing so. In general, when I deliberate at a time $t_{i} \mathrm{I}$ do so by $\varphi$-ing where my $\varphi$-ing is an event and constituent of my process of deliberation. Given this, one way to further the plausibility of the suggestion that deliberation is selfconscious is to ask the following question. When I deliberate at a time $t_{i}$ by $\varphi$-ing what makes it the case that the event of $\varphi$-ing qualifies as a constituent of a process of deliberation? A promising way to go about answering this question is to say that what I am up to when deliberating is settled in part by what I take myself to be up to. On this suggestion, my taking it that I am deliberating when $\varphi$-ing is part of what settles that I am deliberating by $\varphi$-ing when I do so. ${ }^{7}$ When I deliberate by $\varphi$-ing, that is, I must believe that I am doing so where this belief in part settles that I am deliberating by $\varphi$-ing and thus that the event which is my $\varphi$-ing is in fact a constituent of a process of reasoning. Plausibly I thereby know that I am deliberating whenever I do so by $\varphi$-ing. Deliberation is in this way self-conscious and that one is deliberating is a luminous condition.

Plausible candidates for luminous events and processes have been identified. The candidates are occurrences of a distinctive kind: those the occurrence of which depends on one's taking it that events or processes of the kind in question are occurring. Furthermore, the candidates identified are not mere curiosities. They are rather paradigm constituents of the stream of consciousness - central examples of the kinds of events and processes which make up our conscious mental lives. If Williamson's argument is ineffective against the suggestion that such candidates are luminous it thus fails to establish what it is alleged to: that there are no significant and non-trivial luminous conditions. ${ }^{8}$

\footnotetext{
${ }^{7}$ I say that the belief is only part of what settles that I am deliberating since more may be required. For instance, my $\varphi$-ing might also need to follow other events which are apt to be constituents of a process of deliberation.

8 As an anonymous reviewer noted, some might worry about whether this would really amount to a vindication of my claim that even if Williamson's argument shows that there are no significant luminous states it can still be maintained that there are significant luminous events and processes. If that one is judging and that one is deliberating are luminous conditions it might be thought that there are thereby luminous states. The state of being such that one is judging and the state of being such that one is deliberating (assuming there are such states) might be thought to be luminous if judgment is a kind of luminous event and if deliberation a kind of luminous process. Supposing this is correct then my conclusion needs reformulating slightly. Even if we take Williamson's argument to be effective in the cases which are typically discussed it is not effective against the suggestion that there are some significant luminous events and processes and corresponding luminous states. My conclusion could be stated by saying that Williamson's argument does not speak against the suggestion that there are luminous states of a distinctive kind. But to state my conclusion that way would be to obscure why the corresponding conditions are plausibly luminous. Judgment and deliberation are plausibly self-conscious because of the way in which they are things which we consciously $d o$. The case for their luminosity turns on their being kinds of conscious occurrences. Why Williamson's anti-luminosity argument fails to speak against this suggestion would also be obscured if my conclusion was stated in the way in question. It is because they are the kinds of conscious occurrences that they are that Williamson's argument fails to speak against the suggestion that judgment and deliberation are luminous (see below).
} 


\section{The argument's failure to apply}

Williamson's anti-luminosity argument cannot get a grip in the cases of concern. This is because the conditions of concern-that one is judging and that one is deliberating - are not conditions of a kind which can be gradually gained or lost in the required way.

Consider the judgment case first. Judgment is a plausibly a kind of luminous event and that one is judging is plausibly a luminous condition correspondingly. Furthermore, that one is judging is not a condition of a sort which can be gradually gained or lost in the way required for Williamson's anti-luminosity argument to get a grip. There is no possible series of times where one is judging at one point, not judging at another, and where the change in question is gradual such that an analogue of $\left(\mathrm{I}_{i}\right)$ is thereby plausibly true. As was noted, $\left(\mathrm{I}_{i}\right)$ is plausible when it comes to a series in which one is cold at the start and hot at the end because the difference between any case $\alpha_{i}$ and $\alpha_{i+1}$ is imperceptibly small from one's point of view. It is plausible to think that I could not know that I am cold in $\alpha_{i}$ if imperceptibly different circumstances in which I am not cold could so easily have obtained at the time of $\alpha_{i}$. A series of the required kind in the judgment case would be one in which at $t_{o}$ one is judging and at $t_{n}$ one is not. But judgment is a kind of conscious event. Given this, things at the moment after one has made a given judgment will not be imperceptibly different from one's point of view to things when one is judging from one's point of view. There is then no plausibility to an analogue of $\left(\mathrm{I}_{i}\right)$ according to which if I am to know that I am judging then I must be judging the moment after. To say this would be no more plausible than it would be to say that for me to know that I am seeing a flash of light when I do I must see the flash of light the moment after too. In general, when an act of judgment is completed, a conscious change thereby occurs such that there is no plausibility to the claim that if I am to know that I am judging at $t_{i}$ I must be judging at $t_{i \pm 1}$.

The same goes for the deliberation case. A series of the kind required for Williamson's anti-luminosity argument to get a grip would be one in which at $t_{0}$ one is deliberating and at $t_{n}$ one is not. Again, for any such series there will be no plausibility to the claim that if at $t_{i}$ one is to know that one is deliberating then at $t_{i+1}$ one must be deliberating. Deliberation, as seen, is a process constituted by the occurrence of a series of events. I might, for instance, judge that $p$, suppose that $q$ and infer $r$, deliberating by doing so. Suppose that I do not then go on to deliberate further. Things from my point of view at the moment after I have inferred $r$ will not be imperceptibly different to things from my point of view when I do make the inference. It may of course be true that when I deliberate by $\varphi$-ing that I could easily not have been doing so. But when I am aware of my seeing a flash it may equally be true that I could easily not have been seeing the flash-I might have looked the other way or blinked and missed it. There is then no plausibility to an analogue of $\left(\mathrm{I}_{i}\right)$ according to which if I am to know that I am deliberating when I infer $r$ then I must be deliberating at the moment after. In general, when I stop or start deliberating a conscious change thereby occurs such that there is no plausibility to the claim that if I am to know that I am deliberating at $t_{i}$ when my deliberation begins or ends I must be deliberating at $t_{i \pm 1}$. 
I have suggested that the claim that knowledge is undermined by a nearby possibility of falsehood lacks plausibility unless, had that possibility obtained, one would have been in imperceptibly different circumstances from one's point of view to those in which one is in fact in. But judgment is a kind of conscious event. Whenever one goes from consciously judging to not (or vice versa) a conscious and perceptible change does thereby occur. Deliberation is a kind of conscious process and thus the same goes whenever one goes from consciously deliberating to not (or vice versa). These do not seem to be cases in which a series is possible such that an analogue of $\left(\mathrm{I}_{i}\right)$ is plausible. It appears, then, that for such cases an anti-luminosity argument cannot be effectively made. It can thus be maintained that judgment and deliberation are selfconscious, and that there are luminous events and processes in the face of Williamson's anti-luminosity argument.

\section{Reinstating the argument}

As I noted, Williamson's anti-luminosity argument can be applied to any condition which is such that it is possible to have a series of times where the condition obtains at one point and does not at another, where the change in question occurs gradually such than an analogue of $\left(\mathrm{I}_{i}\right)$ plausibly holds. And this will be possible for any condition of a sort which can be gradually gained or lost such that the change in how things are from one time to the next is imperceptibly small from one's own point of view. I have argued that Williamson's argument is more limited in scope than is commonly thought. Even if successful, the argument does not undermine the Cartesian thought that we have a cognitive home. For all Williamson shows, there may be significant luminous events and processes.

What I have exploited is that series of the sort needed in order for Williamson' anti-luminosity argument to get a grip are not possible in the cases of judgment and deliberation. In the judgment case, for instance, when one goes from judging to not judging a conscious and perceptible change thereby occurs. Given this, there is no series of times where one is judging at the beginning, not judging at the end, and where the change in how things are from one time to the next is imperceptibly small from one's own point of view. An analogue of $\left(\mathrm{I}_{i}\right)$ thus fails to obtain. The same is so in the case of deliberation. When one goes from deliberating to not, a conscious and perceptible change thereby occurs.

However, as two anonymous reviewers observed, I ought to see if it is possible to reinstate the anti-luminosity argument in the above cases. It does not suffice for my purposes merely to show that the anti-luminosity argument as stated by Williamson does not apply in the cases considered. It must be asked whether there is a possible extension of the anti-luminosity argument apt to refute my suggestion that judgment and deliberation are luminous. I will consider how this might be done in the case of judgment. My suggestion will be that that the natural way to do so fails and that same is plausibly true in the deliberation case.

When one goes from judging to not a perceptible change thereby occurs. Given this, one cannot gradually transition from judging to not where the change from one's point of view from one time to the next is imperceptible. It is because of this that a 
series of a sort needed to run Williamson's anti-luminosity argument cannot be set up in the judgment case. But consideration of a different kind of series might be thought to yield an anti-luminosity argument in this case. The relevant kind of series is one in which, rather than gradually transitioning from judging to not, one is continuously making distinct judgments at the beginning of the series and doing something else at the end, where the change in one's circumstances over time is gradual. One might, for instance, be continuously judging that $p$ at the beginning of the series and merely saying to oneself that $p$ at the end. If one judges that $p$ at a time $t_{i}$ in such a series one will not be in imperceptibly different circumstances from one's point of view at $t_{i+1}$ at which one is no longer making that particular judgment. Nonetheless, it seems that if one judges that $p$ at $t_{i}$, and if at a time shortly after having made the judgment one takes oneself to be judging that $p$ in circumstances which are similar from one's point of view to one's circumstances at $t_{i}$, then one must in fact be judging that $p$ at the latter time. Suppose, for instance, that one is in fact mistaken in taking oneself to be judging that $p$ at the latter time. This would seem to undermine one's knowledge that one is judging at $t_{i}$. Plausibly one could not know that one is judging that $p$ at $t_{i}$ if one could so easily have been wrong about that one is judging that $p$ in circumstances which are similar to one's circumstances at $t_{i}$ from one's point of view. If such a series is possible then it seems that an appropriate analogue of $\left(\mathrm{I}_{i}\right)$ holds and that an anti-luminosity argument will thereby undermine the claim that judgment luminous.

My response will be to suggest that we lack reasons to think that such a series is possible. An attempt to reinstate the anti-luminosity argument in the above way will have to trade on the possibility of mistakenly taking oneself to be judging that $p$ in circumstances which are similar from one's point of view to those in which one is in fact judging that $p$. In fact, it seems that there cannot be errors of this kind. The relevant kind of possibility is one in which one takes oneself to be judging that $p$ in circumstances which are similar from one's point of view to those when one is in fact judging that $p$, but where one is in fact mistaken in taking oneself to be judging that $p$. Is this really possible?

In order to answer this question, it will help to look again at the nature of judgment. If judgment is merely taken to be an event of belief formation then it might thereby be thought that one can mistakenly take oneself to be judging. After all, as already noted, we do often come to believe without making conscious judgments. One might mistakenly believe that this is occurring and it might be thought that that would just be for one to mistakenly take oneself to be judging. But this thought trades on a mistaken conception of judgment. ${ }^{9}$ Judgment is a kind of conscious mental event and a kind of conscious act (Shah and Velleman 2005, p. 503; Soteriou 2013, Chapter 10). It is not merely an event of belief formation. Of course, judgment can and often does yield belief. But one can judge that $p$ without coming to believe $p$. For instance, judging that $p$ does not yield belief that $p$ when one already believes that $p$ (Soteriou 2013, p. 237; Toribio 2011, p. 346). Judgment that $p$ can even fail to yield belief that $p$ in cases

\footnotetext{
9 Or simply changes the subject. One could use 'judgment' to mean events of belief formation. But that one can mistakenly take oneself to be judging in this sense does not undermine the suggestion that judgment — understood as a kind of conscious act of acceptance-is luminous.
} 
in which one does not already believe that $p$. This last point is clearly illustrated by Peacocke with the following example:

Someone may judge that undergraduate degrees from countries other than their own are of an equal standard to her own, and excellent reasons may be operative in her assertions to that effect. All the same, it may be quite clear, in decisions she makes on hiring, or in making recommendations, that she does not really have this belief at all (1998, p. 90).

Such examples make clear that we can make judgments without thereby coming to believe that which we judge to be the case (see also Cassam 2010, pp. 81-82; Shah and Velleman 2005, p. 507; Sosa 2005, p. 9).

In the light of this we can consider again what it would take for there to be a possibility of the sort required for the above reinstatement of the anti-luminosity argument. The possibility must be one in which a conscious event occurs, where from one's point of view things are like when one judges that $p$. Furthermore, one must take oneself to be judging that $p$, yet in fact be mistaken in taking oneself to be doing so. But if a conscious event occurs where one takes oneself to be judging that $p$ and where things are like they are when one judges that $p$ from one's point of view, what grounds could there be to deny that this is simply a case in which one really does judge that $p$ ? As has been seen, if the judgment in fact fails to instil belief that $p$ this is not grounds to deny that one is judging that $p$. It seems that if a conscious event occurs where things are as if one is judging that $p$ and where one takes oneself to be doing so, then one simply is judging that $p$. Given this, the burden is on the advocate of the imagined anti-luminosity argument to argue that one could mistakenly take oneself to be judging in such circumstances. And given that judgment does not need to yield belief in order to occur grounds to say that such mistakes are possible seem to be missing.

An advocate of the claim that judgment is luminous, that is, can say the following. There do not seem to be possibilities of the kind required to reinstate the anti-luminosity argument against the suggestion that judgment is self-conscious. That is because if one takes oneself to be judging in circumstances like those when one is in fact judging from one's point of view, then grounds seem to thereby be missing to deny that the case is one in which one really is judging. In order to respond, an advocate of the imagined anti-luminosity argument would need to explain why we should think that one could take oneself to be judging in circumstances like those when one in fact judges from one's point of view and yet be mistaken in taking oneself to be doing so. And, as we have seen, that one could take oneself to be judging in a case in which one is not coming to believe what one accepts is not grounds to think that there are possibilities of the relevant sort. Judgments can simply fail to yield corresponding beliefs.

In sum, a Williamson-style anti-luminosity argument cannot be made in the case of judgment because when one goes from judging to not judging a conscious and perceptible change thereby occurs. In attempting to reinstate the anti-luminosity argument I considered the possibility of series in which one is continuously making judgments at the beginning and ends up not judging but rather mistakenly taking oneself to be doing so in circumstances which are similar to those when one is judging from one's point of view. If such a series is possible, then an anti-luminosity argument can be 
launched in order to undermine the luminosity of judgment. However, I have suggested that reflection on the nature of judgment reveals that no such series is possible. If one is in circumstances like those when one judges from one's point of view and one takes oneself to be judging, then we lack grounds to deny that one simply is judging. We lack grounds to think that mistakes of the required kind are in fact possible. An analogous defence of luminosity could be given in the deliberation case, although the case does introduce additional complications. However, since a defence of the claim that judgment is luminous suffices for my purposes I will set the deliberation case aside. The above defence of the claim that judgment is luminous-as well as the fact that an analogous case can plausibly be made in the case of deliberation-suffices to show that for all the anti-luminosity argument shows there are significant luminous conditions.

\section{Conclusion}

The standard way to object to Williamson's anti-luminosity argument is to object to $\left(\mathrm{I}_{i}\right)$ and its analogues in the cases which are Williamson's focus (e.g. Neta and Rohrbaugh 2004; Ramachandran 2009; Weatherson 2004; Wong 2008). The debate has thus centred around whether $\left(\mathrm{I}_{i}\right)$ and its analogues hold when it comes to candidate luminous states. But there is another way to object. Plausibly luminous conditions can be identified for which no series is possible such that an analogue of $\left(\mathrm{I}_{i}\right)$ can be motivated. ${ }^{10}$ This can be done even if it is admitted that $\left(\mathrm{I}_{i}\right)$ and its analogous may well be correct in the cases that are usually of concern in the luminosity debate: cases of allegedly luminous states and the corresponding conditions.

My conclusion is that the anti-luminosity argument has been taken to have wider application than it in fact has. This can be seen to be so regardless of its success in the cases which it has been applied to. Even if Williamson shows that there are no significant luminous states, there are plausibly significant luminous events and processes. And the candidates investigated are not such that a series can be set up where an analogue of $\left(\mathrm{I}_{i}\right)$ can be maintained and an anti-luminosity argument launched. Furthermore, the events and processes investigated should have been among the most plausible candidates for luminosity to begin with, being constituents of the stream of consciousness. They may simply have been overlooked due to the general tendency to focus on mental states rather than events and processes in recent philosophy of mind

\footnotetext{
10 I am not the first to pursue a strategy of this kind. Duncan (2017) argues that there are significant luminous conditions of a kind overlooked by Williamson and others: those specified with "direct phenomenal concepts" such as that my experience is thus. His claim is that there is a specific kind of state to which the anti-luminosity argument does not apply. As seen, my claim has instead been that there are significant events and processes which are plausibly luminous and to which the anti-luminosity argument does not apply. This can be maintained even if it is admitted that there are no significant luminous states (except perhaps for those trivially secured by the existence of luminous occurrences-see footnote 8 above). The potentially luminous conditions which have been identified are also quite different to those discussed by Duncan (2017). The conditions in question have been those which obtain when they do because one's beliefs about what one is consciously doing determine what is in fact occurring. No appeal to "direct phenomenal concepts" needs to be made in order to defend the existence of such conditions.
} 
and epistemology. How this tendency towards a narrow focus can lead us astray is thereby exemplified by the luminosity debate.

Acknowledgements I am grateful to three anonymous referees at Synthese for their helpful comments. I would also like to thank Paul Doody for comments on a draft and Matt Soteriou for discussion. The preparation of this article was supported by an LAHP doctoral studentship, Grant No. AH/L503873/1.

Open Access This article is distributed under the terms of the Creative Commons Attribution 4.0 International License (http://creativecommons.org/licenses/by/4.0/), which permits unrestricted use, distribution, and reproduction in any medium, provided you give appropriate credit to the original author(s) and the source, provide a link to the Creative Commons license, and indicate if changes were made.

\section{References}

Cassam, Q. (2010). Judging, believing and thinking. Philosophical Issues, 20(1), 80-95.

Chrisman, M. (2016). Epistemic normativity and cognitive agency. Noûs. https://doi.org/10.1111/nous. 12184.

Crane, T. (2013). Unconscious belief and conscious thought. In U. Kriegel (Ed.), Phenomenal intentionality (pp. 156-173). Oxford: Oxford University Press.

Crowther, T. (2011). The matter of events. The Review of Metaphysics, 65(1), 3-39.

Duncan, M. (2017). What it's like to have a cognitive home. European Journal of Philosophy, 25(1), 66-81.

Hornsby, J. (2012). Actions and activity. Philosophical Issues, 22(1), 233-245.

Jenkins, D. (2018). The role of judgment in doxastic agency. Thought: A Journal of Philosophy, 7(1), 12-19.

Neta, R., \& Rohrbaugh, G. (2004). Luminosity and the safety of knowledge. Pacific Philosophical Quarterly, 85(4), 396-406.

O'Shaughnessy, B. (2000). Consciousness and the world. Oxford: Clarendon Press.

Peacocke, C. (1998). Conscious attitudes, attention, and self-knowledge. In C. Wright, B. Smith, \& C. Macdonald (Eds.), Knowing our own minds (pp. 83-98). Oxford: Oxford University Press.

Ramachandran, M. (2009). Anti-luminosity: Four unsuccessful strategies. Australasian Journal of Philosophy, 87(4), 659-673.

Rödl, S. (2007). Self-consciousness. Cambridge, MA: Harvard University Press.

Rödl, S. (2013). The single act of combining. Philosophy and Phenomenological Research, 87(1), 213-220.

Shah, N., \& Velleman, J. D. (2005). Doxastic deliberation. Philosophical Review, 114(4), 497-534.

Sosa, E. (2005). Dreams and philosophy. Proceedings and Addresses of the American Philosophical Association, 79(2), 7-18.

Soteriou, M. (2013). The mind's construction: The ontology of mind and mental action. Oxford: Oxford University Press.

Srinivasan, A. (2015). Are we luminous? Philosophy and Phenomenological Research, 90(2), 294-319.

Steward, H. (1997). The ontology of mind: Events, processes, and states. Oxford: Oxford University Press.

Steward, H. (2013). Processes, continuants, and individuals. Mind, 122(487), 781-812.

Strawson, G. (2003). Mental ballistics or the involuntariness of spontaniety. Proceedings of the Aristotelian Society, 103(3), 227-257.

Toribio, J. (2011). What we do when we judge. Dialectica, 65(3), 345-367.

Weatherson, B. (2004). Luminous margins. Australasian Journal of Philosophy, 82(3), 373-383.

Williamson, T. (2000). Knowledge and its limits. Oxford: Oxford University Press.

Wong, W.-H. (2008). What Williamson's anti-luminosity argument really is. Pacific Philosophical Quarterly, 89(4), 536-543. 